\title{
Ranibizumab, Verteporfin Photodynamic Therapy or Observation for the Treatment of Myopic Choroidal Neovascularization: Cost Effectiveness in the UK
}

\author{
Lindsay Claxton · Bill Malcolm • Matthew Taylor • \\ Jennifer Haig $\cdot$ Claudia Leteneux
}

Published online: 10 October 2014

(c) The Author(s) 2014. This article is published with open access at Springerlink.com

\begin{abstract}
Purpose The aim of this study was to evaluate the cost effectiveness of ranibizumab compared with verteporfin photodynamic therapy (vPDT) or no treatment (observation) in patients with visual impairment due to myopic choroidal neovascularization (CNV).

Methods A Markov model with health states defined by best-corrected visual acuity and a 3-month cycle length was developed. It had a healthcare provider (UK National Health Service and personal social services) perspective, a lifetime time horizon, and was based on 2011 prices; future costs and health outcomes were discounted at $3.5 \%$ per annum. Baseline characteristics were based on the phase III RADIANCE (Ranibizumab and vPDT Evaluation in Myopic CNV) study, and year 1 health-state transitions were based on this and the VIP (Verteporfin in Photodynamic Therapy) study. Extensive sensitivity analyses tested the robustness of the model.
\end{abstract}

Electronic supplementary material The online version of this article (doi:10.1007/s40266-014-0216-y) contains supplementary material, which is available to authorized users.

L. Claxton $(\bowtie) \cdot$ M. Taylor

York Health Economics Consortium, University of York, York

YO10 5DD, UK

e-mail: lindsay.claxton@york.ac.uk

B. Malcolm

Novartis Pharmaceuticals UK Limited, Frimley Business Park,

Surrey, UK

J. Haig

Optum, Burlington, ON, Canada

C. Leteneux

Novartis Pharma AG, Basel, Switzerland
Results The lifetime cost of treating myopic CNV with ranibizumab was $£ 12,866$, whereas vPDT and observation were associated with total costs of $£ 14,421$ and $£ 8,163$, respectively. Ranibizumab treatment produced higher cumulative quality-adjusted life-years (QALYs; 12.99) than vPDT (12.60) or observation (12.45). Ranibizumab treatment was therefore dominant, with greater health gains and lower overall costs than vPDT. Ranibizumab was cost effective compared with observation, with an incremental cost-effectiveness ratio of $£ 8,778 / \mathrm{QALY}$. In the probabilistic sensitivity analysis, ranibizumab had a $100 \%$ and $88 \%$ probability of being cost effective compared with vPDT and observation, respectively, at a willingness-topay threshold of $£ 20,000 / \mathrm{Q} A L Y$.

Conclusion This study indicates that ranibizumab therapy is dominant over vPDT for the treatment of visual impairment due to CNV secondary to pathologic myopia in the UK healthcare setting and cost effective compared with observation. 


\section{Key Points}

Ranibizumab is a vascular endothelial growth factor A inhibitor licensed for the treatment of visual impairment due to choroidal neovascularization (CNV) secondary to pathologic myopia.

A cost-utility model was developed using the pivotal phase III RADIANCE study results. This indicated that the health gains associated with ranibizumab treatment over a patient's lifetime are higher than those associated with the previous standard of care, verteporfin photodynamic therapy (vPDT), or managing patients through observation.

Ranibizumab treatment was associated with lower lifetime costs than vPDT and is therefore an economically dominant alternative to vPDT for the treatment of myopic CNV in the UK healthcare setting. Ranibizumab treatment is cost effective compared with observation.

\section{Introduction}

Pathologic myopia is a progressive condition characterized by axial elongation and degenerative changes in the posterior segment of the eye [1]. Choroidal neovascularization (CNV) is characterized by the growth of blood vessels under the retinal pigment epithelium or retina; these vessels can rupture, leading to the accumulation of blood and fluid within layers of the retina [2]. CNV secondary to pathologic myopia, also known as myopic $\mathrm{CNV}$, is one of the major causes of blindness and visual impairment worldwide [3, 4].

Verteporfin (Visudyne ${ }^{\circledR}$, Novartis Pharma AG, Switzerland) photodynamic therapy (vPDT) has replaced laser photocoagulation as the treatment of choice for myopic CNV for subfoveal lesions [3]. However, vPDT does not significantly improve patients' vision and may not control the underlying neovascularization disease activity $[5,6]$. In the 24-month Verteporfin in Photodynamic Therapy (VIP) trial, the proportion of patients whose best-corrected visual acuity (BCVA) remained stable was higher with vPDT than with placebo at 12 months (72 vs $44 \%, p<0.01$ ), but this was no longer significant at 24 months (64 vs $49 \%$, $p=0.11$ ) [5]. The median change in BCVA from baseline to 24 months ranged from -1 to 1 letter with vPDT and -5 to -9 letters with placebo (measured using the ETDRS [Early Treatment Diabetic Retinopathy Study] chart). There is therefore an unmet need for treatment that improves vision in patients with visual impairment secondary to myopic CNV.
Ranibizumab (Lucentis ${ }^{\circledR}$, Novartis Pharma AG, Switzerland) is a recombinant, humanized, monoclonal antibody fragment designed to inhibit the active forms of vascular endothelial growth factor A (VEGF-A) [7]. VEGF-A is important in the pathogenesis of CNV, stimulating the growth of new blood vessels and increasing vascular leakage $[8,9]$. Ranibizumab has demonstrated clinical efficacy in patients with visual impairment secondary to wet age-related macular degeneration [10-12], diabetic macular oedema [13-17] and macular oedema following retinal vein occlusion [18-22], and is widely licensed and reimbursed across these indications. The most recent indication is for the treatment of visual impairment due to CNV secondary to pathologic myopia.

The RADIANCE (Ranibizumab and vPDT Evaluation in Myopic CNV) study was a 12-month, phase III study in which patients were randomized to either ranibizumab or vPDT, plus appropriate shams [23]. To avoid denying patients an effective treatment, patients randomized to vPDT could switch to ranibizumab from month 3 onwards at the treating investigator's discretion. Indeed, $73 \%(40 / 55)$ of patients randomized to vPDT did switch to ranibizumab during the study, including two patients who switched before month 3 . The primary endpoint, the mean average change from baseline in BCVA at 3 months, was +10.5 and +10.6 letters in patients randomized to ranibizumab (administered according to disease stabilization or disease activity criteria, respectively) compared with +2.2 letters in the vPDT group $(p<0.0001$ versus ranibizumab, stratified Cochran-MantelHaenszel test) [23]. Improvements in BCVA in the ranibizumab groups were sustained for the duration of the study. Patient-reported visual functioning, as measured by the 25-item National Eye Institute Visual Functioning Questionnaire (NEI VFQ-25), was improved in the ranibizumab groups from baseline and the difference compared with vPDT was significant at 3 months (measured using the composite score, $p<0.05$ [24]).

Here we present an economic analysis of ranibizumab in the treatment of visual impairment due to myopic CNV. We have used a Markov health-state transition model and have incorporated findings from the RADIANCE study and VIP trial to compare the costs and benefits of treating patients with ranibizumab with those of $\mathrm{vPDT}$ treatment or observation only, adopting a UK healthcare provider perspective.

\section{Methods}

\subsection{Model Structure}

A Markov decision-analytical model was developed to predict the long-term costs and health outcomes of ranibizumab treatment for visual impairment due to myopic 


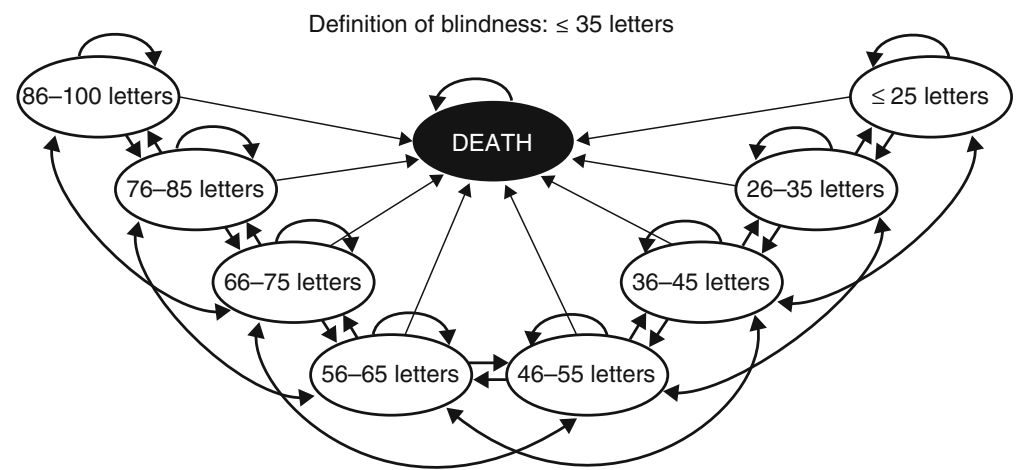

\begin{tabular}{|l|l|}
\hline BCVA \\
\hline ETDRS letters & Snellen equivalents \\
\hline $86-100$ & $20 / 16-20 / 10$ \\
\hline $76-85$ & $20 / 32-20 / 20$ \\
\hline $66-75$ & $20 / 64-20 / 40$ \\
\hline $56-65$ & $20 / 80-20 / 50$ \\
\hline $46-55$ & $20 / 125-20 / 80$ \\
\hline $36-45$ & $20 / 200-20 / 125$ \\
\hline $26-35$ & $20 / 320-20 / 200$ \\
\hline$\leq 25$ & $<20 / 320$ \\
\hline & \multicolumn{2}{|l}{} \\
\hline
\end{tabular}

Fig. 1 Markov model of health states and possible patient transitions. The transition probabilities were based on patients moving between any two states, so the arrows as depicted on this schematic would extend to all other states. The arrows have not been completed here for every possible state to maintain legibility. $B C V A$ best-corrected visual acuity, ETDRS Early Treatment Diabetic Retinopathy study
CNV compared with vPDT or observation only. In the Markov structure, patients were categorized by health state and could move between states at the end of each 3-month cycle according to their level of visual acuity. Half-cycle correction was used. The model had eight health states defined by the BCVA in the treated eye and a ninth absorbing death state (Fig. 1). The BCVA health states are defined by 10-letter (two-line) BCVA ranges between 25 letters or less and 86-100 letters (on the ETDRS chart). A 10-letter gain is associated with clinically relevant changes in the patient's vision and vision-related quality of life [25].

BCVA scores at baseline were taken from the RADIANCE study (treated eyes of patients receiving ranibizumab by disease activity criterion, full analysis set). The starting age of patients was 55 years based on the mean age of patients in the RADIANCE study [23] and $15 \%$ were assumed to have bilateral disease at the start of the model [26, 27]. Patients received either ranibizumab or vPDT over 2 years and treatment was resumed only in cases of recurrence (Table 1). The annual recurrence rate was based on expert opinion (two international advisory boards comprising experts chosen for their high level of expertise in retinal disease) and assumed to be $6 \%$ following treatment completion (consensus was reached by discussion). This was a conservative estimate and is supported by recurrence data from a long-term study in which $46 \%$ of eyes treated with vPDT and/or anti-VEGF experienced at least one recurrence over a mean follow-up of 71 months [28]. At baseline, $21 \%$ of patients were treated in their better-seeing eye (BSE; defined as such when the BCVA letter score at baseline was higher than the score for the non-study eye) [29] estimated from the RADIANCE study.

The proportion of patients treated in their BSE in each health state is shown in Table 2. The model is dynamic in that it allows the treated eye to change from being the worse-seeing eye (WSE) to the BSE as BCVA improves.
This was modelled using a probability matrix of the study eye being the BSE by level of visual acuity (Table 2).

Transition probabilities (TPs) were calculated for each 3-month cycle depending on the treatment received. Patients could transition between any health state in each cycle, according to their change in BCVA score over the cycle. For the first year, patient-level data were used to calculate separate TPs for each BCVA health state, allowing for 64 unique TPs $(8 \times 8)$ for each 3 -month time period (see electronic supplementary material [ESM], Online Resource 1 ). The $8 \times 8$ matrix was able to model the 'ceiling effect' of gains in visual acuity, as patients with high baseline visual acuity have less potential for improvement than those with poor baseline vision. Consequently, this method predicted the trial results more accurately than two other methods tested (constant TPs across all BCVA levels or constant probabilities for all states other than the two highest health states). The basecase TPs in each cycle in year 1 were varied in sensitivity analysis by multiplying by a factor of 0.5-2.0.

The effect of ranibizumab, vPDT or observation on BCVA was modelled over 1 year. Thereafter, it was assumed that BCVA declined at the same rate irrespective of initial treatment, according to natural history data. In the base-case analysis, a second set of TPs was calculated using data from the natural history study with the longest available follow-up [30] and applied from year 2 onwards to capture the natural decline in BCVA without treatment. The overall probability of a patient's vision deteriorating over the follow-up period was converted to a monthly rate and in turn converted into a 3-monthly probability. A probability of all-cause mortality was included in the model [31] and an increased mortality risk was applied when BCVA was 55 letters or less to reflect increased mortality in patients with BCVA below this level (relative risk of 1.23 , increasing to 1.54 when $\mathrm{BCVA}$ was $\leq 35$ letters) [32]. 
Table 1 Model inputs for treatment and monitoring frequencies and data sources for baseline BCVA the base-case scenario

\begin{tabular}{|c|c|c|c|c|}
\hline $\begin{array}{l}\text { Time } \\
\text { period }\end{array}$ & Treatment & BCVA data source & $\begin{array}{l}\text { Mean number of treatments } \\
\text { administered }\end{array}$ & $\begin{array}{l}\text { Mean number of monitoring } \\
\text { visits }\end{array}$ \\
\hline \multirow[t]{4}{*}{ Year 1} & Ranibizumab & $\begin{array}{l}\text { RADIANCE study (0-12 months) } \\
\text { [23] }\end{array}$ & $3.5[23]$ & $8.5^{\mathrm{a}}$ (assumption) \\
\hline & vPDT & $\begin{array}{l}\text { RADIANCE study (0-3 months) } \\
\text { [23] }\end{array}$ & $3.4[5]$ & $4.0[48]$ \\
\hline & & VIP trial (4-12 months) [5] & & \\
\hline & Observation & VIP trial (0-12 months) [5] & 0 & $4.0[5]$ \\
\hline \multirow[t]{3}{*}{ Year 2} & Ranibizumab & Natural history [30] & $1.0^{\mathrm{b}}$ (expert advice) & 4.0 (assumption) \\
\hline & vPDT & Natural history [30] & 1.7 (VIP trial) [6] & $4.0[48]$ \\
\hline & Observation & Natural history [30] & 0 & 4.0 (assumption) \\
\hline \multirow[t]{3}{*}{ Year 3+ } & Ranibizumab & Natural history [30] & $0^{\mathrm{b}}$ (expert advice) & $0^{\mathrm{b}}($ expert advice $)$ \\
\hline & vPDT & Natural history [30] & 0 (VIP trial) [6] & 0 (VIP trial) [6] \\
\hline & Observation & Natural history [30] & 0 & 4.0 (assumption) $^{\mathrm{c}}$ \\
\hline
\end{tabular}

$B C V A$ best-corrected visual acuity, $m C N V$ myopic choroidal neovascularization, RADIANCE Ranibizumab and vPDT Evaluation in Myopic Choroidal Neovascularization, SmPC Summary of Product Characteristics, VIP Verteporfin in Photodynamic Therapy, vPDT verteporfin photodynamic therapy

${ }^{a}$ This is a conservative assumption; the ranibizumab SmPC states that about 5.5 monitoring visits are expected in year 1 of ranibizumab treatment

${ }^{\mathrm{b}}$ Expert advice was taken from an advisory board of $11 \mathrm{UK}$ ophthalmologists

${ }^{\mathrm{c}}$ For patients undergoing observation, as the disease is not actively being treated it was assumed that they will continue to be monitored up to year 3, as their disease was unlikely to have been cured. For patients receiving treatment, in the absence of long-term data, and informed by expert advice, it was assumed that $\mathrm{mCNV}$ has a limited course, requiring no monitoring visits in year 3

Table 2 Baseline distributions of patients treated in their better-seeing eye (BSE) or worse-seeing eye (WSE) and utility values by BSE/WSE

\begin{tabular}{lllll}
\hline $\begin{array}{l}\text { BCVA health } \\
\text { state (letters) }\end{array}$ & $\begin{array}{l}\text { Patients at } \\
\text { model entry (\%) }\end{array}$ & $\begin{array}{l}\text { Patients whose } \\
\text { treated eye was } \\
\text { their BSE (\%) }\end{array}$ & $\begin{array}{l}\text { Utility when } \\
\text { treated eye } \\
\text { was the BSE }\end{array}$ & $\begin{array}{l}\text { Utility when } \\
\text { treated eye } \\
\text { was the WSE }\end{array}$ \\
\hline $86-100$ & 0 & $50^{\mathrm{a}}$ & 0.850 & 0.850 \\
$76-85$ & 4 & 50 & 0.758 & 0.836 \\
$66-75$ & 20 & 22 & 0.685 & 0.821 \\
$56-65$ & 33 & 22 & 0.611 & 0.807 \\
$46-55$ & 20 & 21 & 0.537 & 0.793 \\
$36-45$ & 13 & 15 & 0.464 & 0.779 \\
$26-35$ & 9 & 10 & 0.390 & 0.764 \\
$\leq 25$ & 1 & $0^{\mathrm{a}}$ & 0.353 & 0.750 \\
Death & 0 & - & 0.000 & 0.000
\end{tabular}

Utilities for the BSE were from a published study; WSE utilities were assumed to be proportional to those for the BSE [33]

$B C V A$ best-corrected visual acuity, RADIANCE Ranibizumab and vPDT Evaluation in Myopic Choroidal Neovascularization

${ }^{a}$ Assumption, no patients were in these groups at baseline in the RADIANCE study

\subsection{Utilities}

Each BCVA health state was assigned a utility weight dependent on whether the treated eye was the patient's BSE or WSE. The proportion of patients whose treated eye was their BSE was matched to baseline BCVA in the RADIANCE study and was modelled dynamically as described earlier [23] (Table 2). Utility weights for the BSE were taken from a study in which visual impairment was simulated using specially designed contact lenses worn by healthy volunteers from the UK and in which time trade-off was used to assess participant's valuation of their health state prior to and following lens installation [33] (Table 2). Utilities for patients treated in the WSE were not available from the literature and various assumptions were required. In the base-case scenario, utility weights for the WSE were assumed to be higher than, or the same as, for the BSE, because visual impairment in the WSE is considered less serious than visual impairment in the BSE. A 0.1 maximum difference in utility values was assumed for 
the WSE between the best and worst possible BCVA health states, as good vision in both eyes is considered 'worth' an additional utility of 0.1 compared with good vision in only one eye. This assumption was based on the National Institute for Health and Care Excellence (NICE) Evidence Review Group guidance issued for ranibizumab in the treatment of visual impairment caused by macular oedema secondary to retinal vein occlusion [34]. The WSE utility curve was anchored at the highest BCVA health state, at which point the utility was the same for the WSE and BSE (ESM, Online Resource 2).

The probability that the study eye is the BSE improves as vision improves. When the BCVA in the treated eye improves to such an extent that it becomes the BSE, the utility value is changed and can be lower than the utility when the eye was the WSE (even though this appears counterintuitive because one might predict that improving vision would result in increased utility). For patients with bilateral disease, utility values were assigned according to BCVA in the BSE as health-related quality of life (HRQoL) is driven by visual acuity in the BSE [35]. For patients who had a recurrence, no change in visual acuity or utility was assumed to occur from the recurrence.

Patients were assumed to experience adverse events (AEs) based on the rates reported in the RADIANCE study for ranibizumab [23] or the VIP trial for vPDT or observation [5] (ESM, Online Resource 3). All AEs that were reported for five or more patients or were suspected to be related to treatment were included. AEs were associated with temporary reductions in utility based on published literature or assumption (range of 0 to -0.02 , see ESM, Online Resource 3). Because timings for AEs were not available, disutilities were calculated as one-off events per patient and applied at entry to the model with the following durations: conjunctival haemorrhage, 1 month; intraocular pressure increase, 1 day; injection site reaction, 8.2 days. In order to assess the comparability of the RADIANCE study and VIP trial populations, baseline characteristics are compared in Online Resource 4 and inclusion/exclusion criteria are compared in Online Resource 5 (ESM). These suggest that the two studies were sufficiently similar to warrant the chosen methodology.

\subsection{Costs}

A full breakdown of costs and sources is given in ESM, Online Resource 6. A UK healthcare provider (National Health Service [NHS] and personal social services [PSS]) perspective was adopted, and a lifetime time horizon used. Future costs and health outcomes were discounted at $3.5 \%$ per annum according to NICE recommendations. Costs from earlier years were inflated to 2011 prices using the Hospital and Community Services Inflation Index [36]. The health-state costs included cost of treatment, administration, monitoring, management of AEs and recurrences, and the long-term cost of blindness. The costs of drug acquisition did not include the ranibizumab patient access scheme discount that is in place in the UK. The cost of administration included the cost of optical coherence tomography plus an injection visit for ranibizumab or an ophthalmologist consultation visit for vPDT. Frequencies of treatment and monitoring were taken from the RADIANCE study or VIP trial (Table 1). The frequency of treatment and the cost and frequency of monitoring were varied extensively in sensitivity analyses. For patients with recurrence, the numbers of treatment and monitoring visits were assumed to correspond to those for year 1 of initial treatment. For patients with bilateral disease, the cost of treatment and monitoring visits was doubled since the fellow eye would incur additional treatment and monitoring visits. The cost of blindness was included when the BSE had a BCVA below 35 letters (that is, both eyes were affected). Resource utilization was based on published data [37] and was higher in the year following diagnosis than in subsequent years as in previous NICE assessments [34].

\subsection{Economic Analysis}

The incremental cost-effectiveness ratio (ICER) was calculated as the ratio of the mean incremental cost and the mean number of incremental quality-adjusted life-years (QALYs) for ranibizumab compared with either vPDT or observation. Net monetary benefit (NMB) was calculated assuming a willingness-to-pay of $£ 20,000 / Q A L Y$ [38]. Using this formulation, higher NMB indicates greater value: NMB greater than $£ 0$ is equivalent to an ICER of less than $£ 20,000 / Q A L Y$. Thus, in the context of this analysis, 'cost effective' is defined as meeting accepted standards of cost effectiveness based on a willingness-topay threshold of $£ 20,000 / Q A L Y$. Deterministic sensitivity analysis was used to explore uncertainty around individual input values to the model, and the effect on the resultant NMB calculated. Probabilistic sensitivity analysis was used to assess the overall level of uncertainty in the model (see ESM, Online Resource 7 for parameters and distributions). The internal validity of the model was checked by a health economist not involved in the development or use of the model. Face validity of the model was validated by two UK ophthalmologists.

\section{Results}

The model predicted that the gain in BCVA in year 1 was greater with ranibizumab than with vPDT (in agreement with the trial data); for both treatments, BCVA gradually 
decreased over subsequent years (Fig. 2). The number of life-years gained was slightly higher with ranibizumab than with vPDT or observation (difference of 0.15 and 0.24 years, respectively), reflecting the higher mortality in patients with low BCVA. Ranibizumab was associated with a QALY gain of 0.39 over vPDT and a QALY gain of 0.54 over observation (Table 3). Lifetime costs were slightly lower for ranibizumab than for vPDT $(-£ 1,555)$ but higher than for observation $(+£ 4,703$, Table 3$)$. As ranibizumab led to greater health gains at lower cost, it was dominant over vPDT (Table 3 ). The NMB was $£ 9,289$ at a willingness-to-pay threshold of $£ 20,000 / \mathrm{QALY}$. Comparison of ranibizumab with observation gave an ICER of $£ 8,778$ /QALY (Table 3), which is lower than the threshold of $£ 20,000-30,000 / \mathrm{QALY}$ often applied in the UK [38]. The NMB was $£ 6,013$.

There were differences in the cost of blindness between treatments. The lifetime cost of blindness was lower for patients receiving ranibizumab $(-£ 3,920)$ or vPDT (2,138) than for patients under observation. Costs of AEs incurred with ranibizumab (£106) or vPDT (£10) were negligible and did not impact on the overall costs.

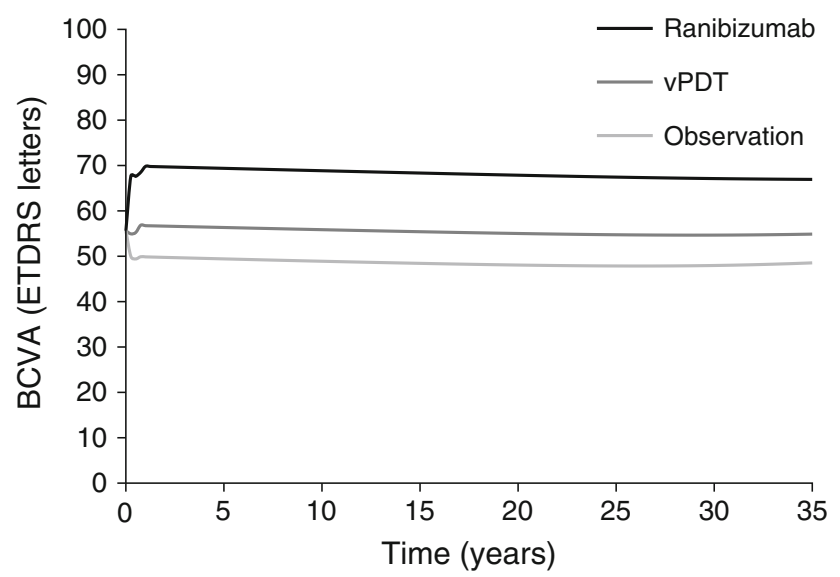

Fig. 2 Visual acuity modelled over time. BCVA best-corrected visual acuity, ETDRS Early Treatment Diabetic Retinopathy study, vPDT verteporfin photodynamic therapy
One-way sensitivity analysis showed that the model results were robust. Comparing with vPDT (Fig. 3a), the model was most sensitive to the maximum utility gain for the WSE, with higher utility values increasing NMB. Ranibizumab was cost effective even when assuming 12 ranibizumab injections in the first year (NMB, £596) and only ceased to be cost effective if 11 or more injections were administered in year 2 , or at a cost over $£ 1,100$ per monitoring visit or a cost over $£ 1,300$ per injection visit at the base case number of injections. Extensive variation of the TPs in year 1 gave results that were consistent with the base-case scenario. Comparing with observation (Fig. 3b), the model was also sensitive to the maximum utility gain for the WSE. Ranibizumab ceased being cost effective when ten injections were administered in the first year, or seven in year 2 , or at a cost over $£ 1,100$ per monitoring visit or a cost over $£ 900$ per injection visit.

The probabilistic sensitivity analysis showed that ranibizumab has a 100 and $88 \%$ probability of being cost effective compared with vPDT and observation, respectively, at a willingness-to-pay threshold of $£ 20,000 / \mathrm{QALY}$ (Fig. 4). Validation of the model by detailed examination of the Markov traces confirmed that the model produced similar results to the study data on which it was based.

\section{Discussion}

This is the first study to evaluate the cost effectiveness of ranibizumab compared with vPDT or observation for the treatment of patients with visual impairment due to myopic $\mathrm{CNV}$. The analysis showed that ranibizumab is dominant over vPDT and was associated with lower lifetime costs and an incremental QALY gain. Ranibizumab was cost effective compared with observation, with an ICER of $£ 8,778$ /QALY. One-way sensitivity analysis showed that the model results were robust, but sensitive to the maximum utility gain for the WSE and number of ranibizumab injections received. Probabilistic sensitivity analysis showed that ranibizumab has a 100 and $88 \%$ probability of

Table 3 Base-case cost-effectiveness results using deterministic values

\begin{tabular}{llllll}
\hline & Ranibizumab & vPDT & Observation & Ranibizumab versus vPDT & Ranibizumab versus observation \\
\hline Cost $(\mathfrak{l})$ & 12,866 & 14,421 & 8,163 & $-1,555$ & $+4,703$ \\
QALYs & 12.99 & 12.60 & 12.45 & +0.39 & +0.54 \\
Life-years & 16.85 & 16.70 & 16.61 & +0.15 & +0.24 \\
NMB (£) & - & - & - & 9,289 & 6,013 \\
ICER (£/QALY) & - & - & - & Dominant & 8,778 \\
\hline
\end{tabular}

The model followed a cohort of 1,000 patients over a lifetime time horizon. The healthcare provider perspective was adopted. Future costs and health outcomes were discounted at $3.5 \%$ per annum

$I C E R$ incremental cost-effectiveness ratio, $N M B$ net monetary benefit, $Q A L Y$ quality-adjusted life-year, $v P D T$ verteporfin photodynamic therapy 
being cost effective compared with vPDT and observation, respectively, at a willingness-to-pay threshold of $£ 20,000$ / QALY.

The anti-VEGF bevacizumab was not included as a comparator in this analysis because it is unlicensed for the treatment of myopic CNV and its use is not considered by NICE to be routine practice across the NHS. Furthermore, after reviewing the quality of evidence for bevacizumab in myopic CNV, the NICE committee concluded that there was insufficient evidence to allow bevacizumab to be included with confidence in a clinical and cost-effectiveness analysis [39].

The improvements in BCVA with ranibizumab compared with vPDT in the RADIANCE study $(+10.5$ and +10.6 letters, respectively, for the disease stabilization and disease activity criteria groups at 3 months) translated to higher utility values in the model, reflecting improved HRQoL after treatment. This gain was achieved with relatively few injections. In the 'disease activity' treatment group, whose characteristics were incorporated into the model and whose treatment corresponded to the ranibizumab myopic CNV label, $50 \%$ of patients required 1-2 injections, $36 \%$ required $3-5$ injections and $14 \%$ required 6-12 injections over the 12-month study [40]. This translated into a mean treatment frequency of 3.5 ranibizumab injections in year 1 of the model. The 3.4 vPDT treatments in year 1 were calculated from treatment frequency in the large VIP trial $[5,6]$. We used a very conservative assumption of 8.5 monitoring visits in year 1 , which is likely to overestimate visits compared with clinical practice. In deterministic sensitivity analysis, increasing the frequency of injections and follow-up visits had a strong effect on the cost effectiveness. However, even assuming 12 injections in year 1, ranibizumab remained cost effective compared with vPDT given 3.4 times per year.

Myopic CNV is a relatively acute condition with a reduced requirement for retreatment compared with other retinal conditions such as neovascular age-related macular degeneration; this is reflected in the low number of ranibizumab injections required in year 2. During the 12-month follow-up in the RADIANCE study, over $50 \%$ of patients treated with ranibizumab according to disease activity criteria required only 1-2 injections and over $60 \%$ did not require further injections from month 6 to month 12 [41]. The NICE review of the model suggested that 1.7 injections in year 2 would be a more reasonable assumption than the one injection included in the model [39]. However, the number of treatments in years 1 and 2 were varied in deterministic and probabilistic sensitivity analyses and did not affect the cost-effectiveness decision. Compared with vPDT, ranibizumab only ceased to be cost effective if 11 or more injections were administered in year 2. Compared with observation, ranibizumab only ceased being cost effective when seven or more injections were administered in year 2.

The RADIANCE results were used to estimate BCVA for year 1 for ranibizumab and for $0-3$ months for VPDT as patients from the vPDT arm were allowed to cross over after 3 months to enable them to benefit from ranibizumab treatment. Thus, data from the VIP trial were used to model BCVA for patients receiving vPDT after 3 months, and the placebo arm data were used to simulate patients under observation only [6]. After 1 year, the decline in BCVA was modelled with the same rate across treatments. This is a conservative approach as recurrence after treatment is likely to be more common in the vPDT group than with ranibizumab [28]. The slow rate of decline in BCVA in subsequent years is consistent with several studies showing that visual acuity gains are maintained over $3-5$ years in a high proportion of patients treated with anti-VEGF therapy [42-44]. Bilateral disease was only modelled by prevalence as patients entered the model because accurate estimation of the incidence rate was not possible owing to the lack of long-term natural history data. Bilateral disease was assumed to double the cost of treatment at the start of the model; for recurrence, the additional costs occurred at the time of the recurrence and included 1 year of treatment and monitoring (overestimating what would happen in clinical practice). Neither variations in the rate of recurrence $(0-12 \%)$ nor the baseline rate of bilateral disease $(0-30 \%)$ affected the dominance of ranibizumab over vPDT. As the mean age of the cohort increased, ranibizumab became less cost effective compared with vPDT or observation as cost savings from avoidance of blindness were not realized.

Utility estimates for the BSE were obtained from a published study that had simulated visual impairment associated with age-related macular degeneration using specially designed contact lenses [33]. BCVA was defined for the BSE and the 'health states' valued by a representative sample of the UK population using the time trade-off technique [33]. The resultant utility values were adjusted to control for important factors known to affect utility (including age and sex). NICE has previously judged that, in the absence of studies reporting utility values for the specific ocular condition, these utility values most accurately reflect the HRQoL associated with visual impairment [34]. The 5-domain European Quality of Life questionnaire was used in the RADIANCE study but the results were not used in the present analysis as the instrument is acknowledged as being insensitive to changes in visual acuity [13]. In sensitivity analysis, varying the utility values by a factor of 0.3-1.3 had little effect on the overall results.

The relationship between utility and BCVA in the WSE is a major source of uncertainty and there are no published studies that can be used to estimate utilities in the WSE. 
Our approach was to assume that utilities would be the same for the BSE and WSE in the highest BCVA health state, while for all other BCVA health states, utilities for the WSE would be proportional to but higher than utilities for the BSE, with the greatest difference between the BSE and WSE at the lowest BCVA health state. Essentially, visual impairment in the BSE has a greater negative effect on utility than impairment in the WSE. This is supported by visual functioning findings [35]. In the base case there was a 0.1 maximum difference in utility values for the WSE between the best and worst possible health states, as good binocular vision is considered 'worth' an additional utility of 0.1 compared with good vision in only one eye [34]. In sensitivity analyses, the maximum utility gain in

(a)

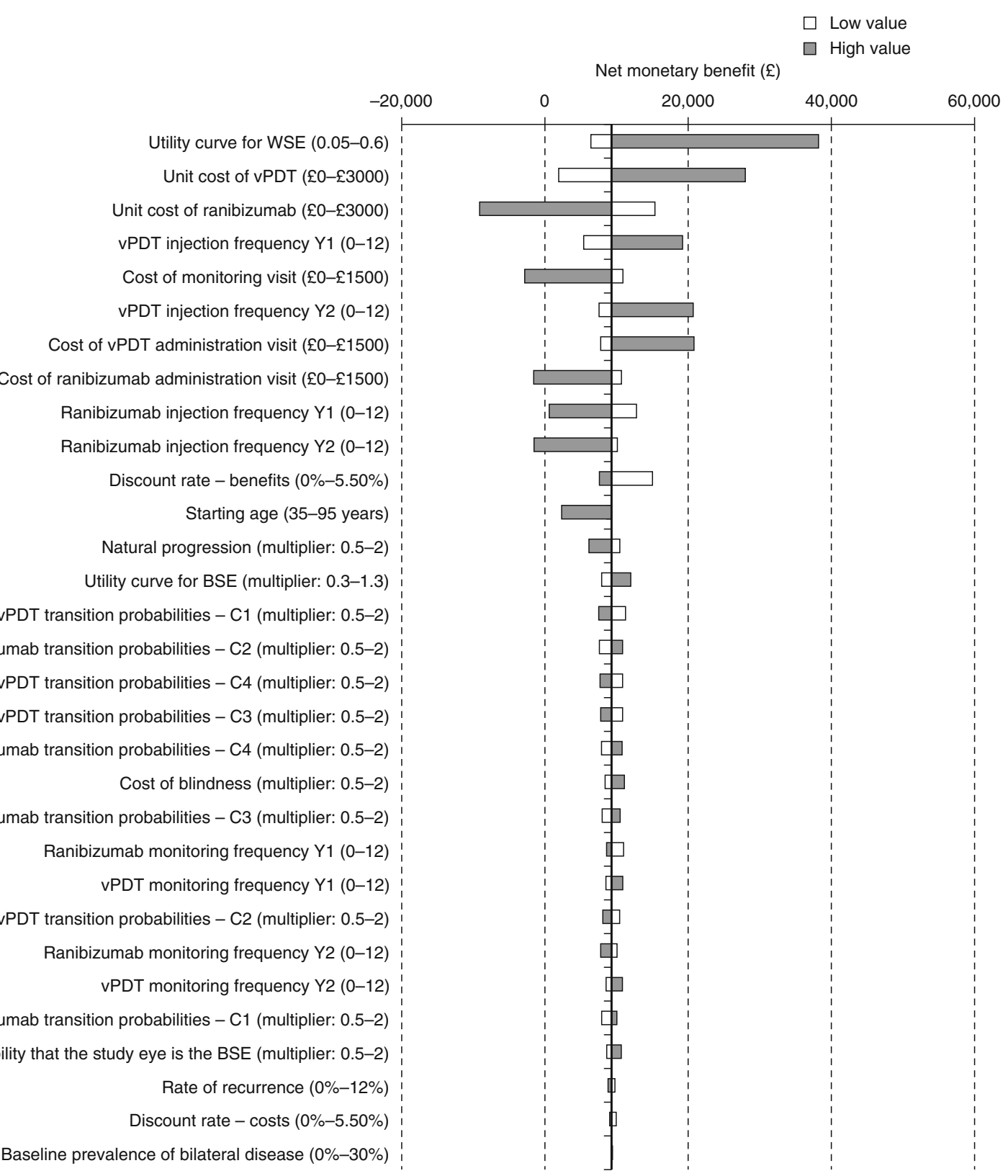

Fig. 3 Tornado plots showing results of one-way sensitivity analysis for ranibizumab compared with a vPDT and $\mathbf{b}$ observation. The $X$ axis represents the net monetary benefit, which for the base-case scenario is $£ 9,289$ for ranibizumab versus vPDT, and $£ 6,013$ for ranibizumab versus observation. Parameters varied are listed in the $Y$ axis. Low

value, lower limit of parameter varied for sensitivity analysis; high value, upper limit of parameter varied for sensitivity analysis; multiplier, multiplication factor for base-case value of parameter. $B S E$ better-seeing eye, $v P D T$ verteporfin photodynamic therapy, WSE worse-seeing eye 
(b)

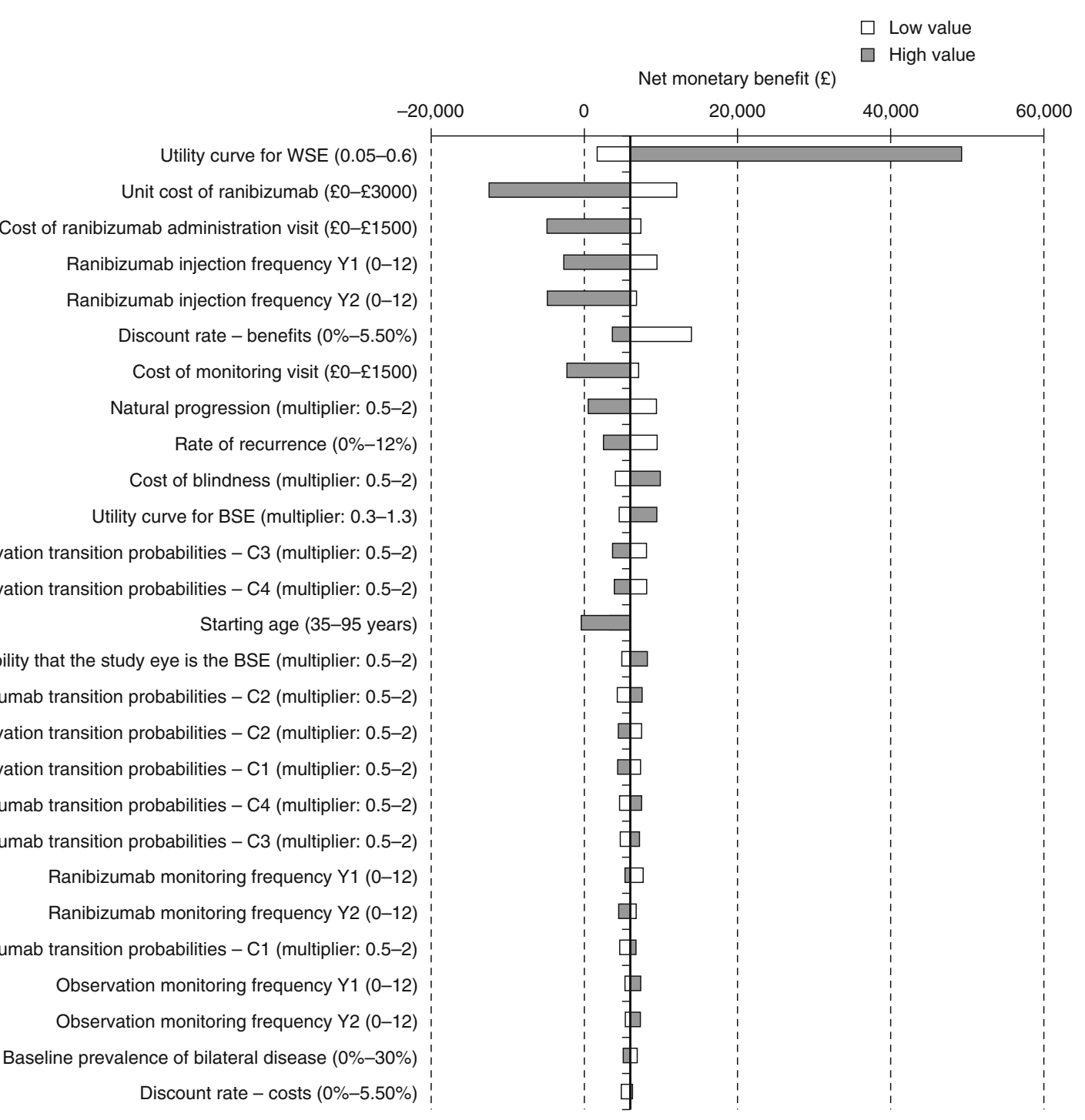

Fig. 3 continued

the WSE had a bigger impact on the results than the other parameters tested. For values of 0.5 or more, the WSE actually had worse utility values than the BSE for the same level of BCVA, which is counterintuitive. At these high estimations, ranibizumab was more cost effective compared with vPDT or observation than in the base-case estimate. Varying the probability that the study eye was the BSE had little effect on the dominance versus vPDT or cost effectiveness versus observation.

Previous models using BCVA health states have maintained a constant proportion of patients whose treated eye is their BSE over the period of the model. The current model is dynamic in that, although the proportion of patients whose treated eye is their BSE is fixed within a health state, as patients transition across health states the overall proportion whose treated eye is their BSE can change over time in the model. Thus, for patients whose treated eye is the WSE, if treatment improves the visual acuity of the treated eye to such an extent that it exceeds the BCVA of the fellow eye, the treated eye becomes the BSE. This can appear counterintuitive, as higher visual acuity in the treated eye may decrease the patient-level utility value, but can be considered a conservative approach as it would underestimate total QALY gain. Furthermore, modelling both BSE and WSE allows more accurate estimations of utility for the patient, reflecting the relative gain from binocular vision.

The study was undertaken from a UK perspective and used UK-specific costs; however, the trial data from the RADIANCE study and VIP trial were international, and the 

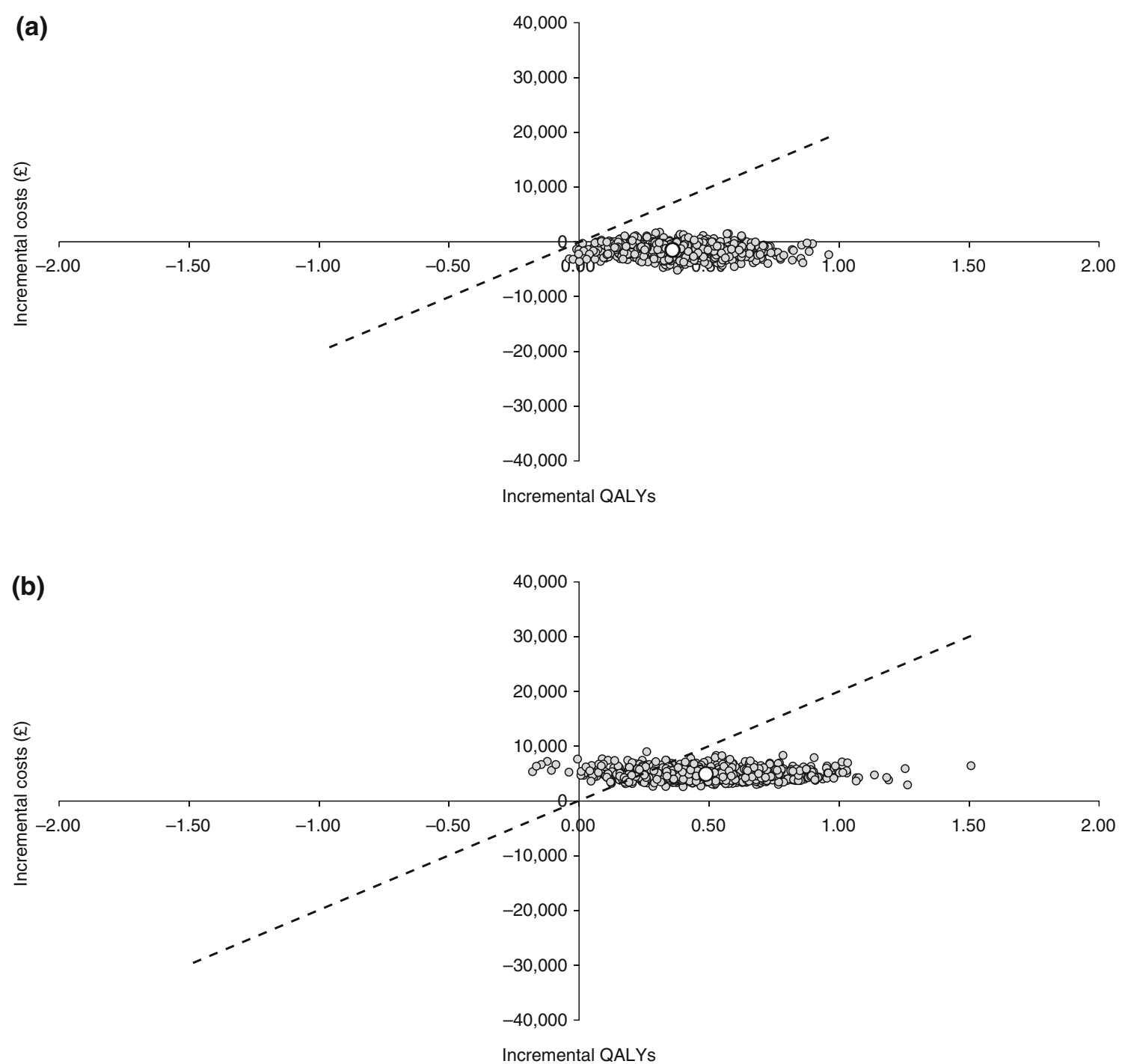

Fig. 4 Scatter plots for probabilistic sensitivity analysis showing cost effectiveness of ranibizumab compared with a vPDT and b observation. $Q A L Y$ quality-adjusted life-year, $v P D T$ verteporfin photodynamic therapy

efficacy and safety results are considered to have good generalizability between populations and healthcare systems. Apart from treatment and visit-related costs, the factors that had the greatest impact on the cost effectiveness were unlikely to be country dependent. The effect of increased mortality associated with low BCVA was not tested in sensitivity analyses. However, the Evidence Review Group on behalf of NICE conducted an exploratory analysis that did vary the mortality multiplier for blindness (BCVA $\leq 35$ letters), with no effect on the cost-effectiveness decision [39].

There is little previous work around the cost effectiveness of treatments in myopic CNV. The one published study in this indication compared vPDT and observation from a US managed care perspective [45]. The base case estimated a QALY gain of 0.037 and an ICER of
US\$214,085/QALY over 1 year. The results are not comparable with the current study because of significant differences in methodology, including a 1-year time horizon, perspective and the absence of costs of blindness in the US study. In wet age-related macular degeneration, diabetic macular oedema and retinal vein occlusion, ranibizumab has been shown to be cost effective (e.g. [34, 37, 46, 47]).

In summary, this economic evaluation shows that ranibizumab is dominant over vPDT and cost effective compared with observation for the treatment of visual impairment due to myopic $\mathrm{CNV}$ using a UK healthcare perspective. This analysis suggests that ranibizumab should be adopted in this patient population.

Acknowledgments The authors take full responsibility for the content of the manuscript but would like to thank Dr Polly Field from 
Oxford PharmaGenesis ${ }^{\mathrm{TM}}$ Ltd for editorial support in developing the manuscript. Hemant Rathi was involved in quality checking the model and reviewing the technical report during model development. This project was funded by Novartis Pharma AG, Basel, Switzerland.

Lindsay Claxton and Matthew Taylor are employees of York Health Economics Consortium, which received funding from Novartis for this work; Bill Malcolm and Claudia Leteneux are employees of Novartis Pharma; Jennifer Haig is an employee of Optum, which received payment from Novartis for this work.

Open Access This article is distributed under the terms of the Creative Commons Attribution Noncommercial License which permits any noncommercial use, distribution, and reproduction in any medium, provided the original author(s) and the source are credited.

\section{References}

1. Neelam K, Cheung CM, Ohno-Matsui K, et al. Choroidal neovascularization in pathological myopia. Prog Retin Eye Res. 2012;31(5):495-525.

2. Green WR, Wilson DJ. Choroidal neovascularization. Ophthalmic Epidemiol. 1986;93:1169-76.

3. Silva R. Myopic maculopathy: a review. Ophthalmologica. 2012;228(4):197-213.

4. Wong TY, Ferreira A, Hughes R. Epidemiology and disease burden of pathologic myopia and myopic choroidal neovascularization: an evidence-based systematic review. Am J Ophthalmol. 2014;157(1):9.e12-25.e12.

5. VIP Study Group. Photodynamic therapy of subfoveal choroidal neovascularization in pathologic myopia with verteporfin. 1-year results of a randomized clinical trial-VIP report no. 1. Ophthalmol. 2001;108(5):841-52.

6. Blinder KJ, Blumenkranz MS, Bressler NM, et al. Verteporfin therapy of subfoveal choroidal neovascularization in pathologic myopia: 2-year results of a randomized clinical trial-VIP report no 3. Ophthalmol. 2003;110(4):667-73.

7. Chen Y, Wiesmann C, Fuh G, et al. Selection and analysis of an optimized anti-VEGF antibody: crystal structure of an affinitymatured $\mathrm{Fab}$ in complex with antigen. $\mathrm{J}$ Mol Biol. 1999;293(4):865-81.

8. Aiello LP, Bursell SE, Clermont A, et al. Vascular endothelial growth factor-induced retinal permeability is mediated by protein kinase $\mathrm{C}$ in vivo and suppressed by an orally effective betaisoform-selective inhibitor. Diabetes. 1997;46(9):1473-80.

9. Funatsu H, Yamashita H, Noma H, Mimura T, Yamashita T, Hori $\mathrm{S}$. Increased levels of vascular endothelial growth factor and interleukin- 6 in the aqueous humor of diabetics with macular edema. Am J Ophthalmol. 2002;133(1):70-7.

10. Rosenfeld PJ, Brown DM, Heier JS, et al. Ranibizumab for neovascular age-related macular degeneration. $\mathrm{N}$ Engl J Med. 2006;355(14):1419-31.

11. Brown DM, Kaiser PK, Michels M, et al. Ranibizumab versus verteporfin for neovascular age-related macular degeneration. N Engl J Med. 2006;355(14):1432-44.

12. Regillo CD, Brown DM, Abraham P, Yue H, Ianchulev T, Schneider S, Shams N. Randomized, double-masked, sham-controlled trial of ranibizumab for neovascular age-related macular degeneration: PIER study year 1 . Am J Ophthalmol. 2008;145(2):239-48.

13. Mitchell P, Bandello F, Schmidt-Erfurth U, et al. The RESTORE study: ranibizumab monotherapy or combined with laser versus laser monotherapy for diabetic macular edema. Ophthalmol. 2011;118(4):615-25.
14. Elman MJ, Aiello LP, Beck RW, et al. Randomized trial evaluating ranibizumab plus prompt or deferred laser or triamcinolone plus prompt laser for diabetic macular edema. Ophthalmol. 2010;117(6):1064.e35-1077.e35.

15. Massin P, Bandello F, Garweg JG, et al. Safety and efficacy of ranibizumab in diabetic macular edema (RESOLVE Study): a 12-month, randomized, controlled, double-masked, multicenter phase II study. Diabetes Care. 2010;33(11):2399-405.

16. Nguyen QD, Shah SM, Khwaja AA, et al. Two-year outcomes of the ranibizumab for edema of the macula in diabetes (READ-2) study. Ophthalmol. 2010;117(11):2146-51.

17. Nguyen QD, Brown DM, Marcus DM, et al. Ranibizumab for diabetic macular edema: results from 2 phase III randomized trials: RISE and RIDE. Ophthalmol. 2012;119(4):789-801.

18. Brown DM, Campochiaro PA, Singh RP, et al. Ranibizumab for macular edema following central retinal vein occlusion: sixmonth primary end point results of a phase III study. Ophthalmol. 2010;117(6):1124.e1-1133.e1.

19. Campochiaro PA, Heier JS, Feiner L, et al. Ranibizumab for macular edema following branch retinal vein occlusion: sixmonth primary end point results of a phase III study. Ophthalmol. 2010;117(6):1102.e1-1112.e1.

20. Kinge B, Stordahl PB, Forsaa V, Fossen K, Haugstad M, Helgesen $\mathrm{OH}$, Seland J, Stene-Johansen I. Efficacy of ranibizumab in patients with macular edema secondary to central retinal vein occlusion: results from the sham-controlled ROCC study. Am J Ophthalmol. 2010;150(3):310-4.

21. Varma R, Bressler NM, Suner I, et al. Improved vision-related function after ranibizumab for macular edema after retinal vein occlusion: results from the BRAVO and CRUISE trials. Ophthalmol. 2012;119(10):2108-18.

22. Kim M, Yu SY, Kim ES, et al. Intravitreal ranibizumab for macular edema secondary to retinal vein occlusion. Ophthalmologica. 2012;227(3):132-8.

23. Wolf S, Balciuniene VJ, Laganovska G, et al. RADIANCE: a randomized controlled study of ranibizumab in patients with choroidal neovascularization secondary to pathologic myopia. Ophthalmol. 2014;121(3):682.e2-696.e2.

24. Ohno-Matsui K, Tan N, Wong TY, et al. Impact of ranibizumab on patient-reported visual functioning in myopic choroidal neovascularization: 3- and 6-month results [presentation 1245]. The Association for Research in Vision and Ophthalmology (ARVO) Annual Meeting; 28-31 October 2013; Seattle (WA).

25. Matza LS, Rousculp MD, Malley K, et al. The longitudinal link between visual acuity and health-related quality of life in patients with diabetic retinopathy. Health Qual Life Outcomes. 2008;6:95.

26. Curtin BJ, Karlin DB. Axial length measurements and fundus changes of the myopic eye. I. The posterior fundus. Trans Am Ophthalmol Soc. 1970;68:312-34.

27. Cohen SY, Laroche A, Leguen Y, et al. Etiology of choroidal neovascularization in young patients. Ophthalmol. 1996;103(8):1241-4.

28. Kang HM, Koh HJ. Ocular risk factors for recurrence of myopic choroidal neovascularization: long-term follow-up study. Retina. 2013;33(8):1613-22.

29. Bressler NM, Chang TS, Suner IJ, et al. Vision-related function after ranibizumab treatment by better- or worse-seeing eye: clinical trial results from MARINA and ANCHOR. Ophthalmol. 2010;117(4):747.e4-756.e4.

30. Yoshida T, Ohno-Matsui K, Ohtake Y, et al. Long-term visual prognosis of choroidal neovascularization in high myopia: a comparison between age groups. Ophthalmol. 2002;109(4): $712-9$.

31. Office for National Statistics. England and Wales Interim Life Tables 2009-2011.2013. http://www.ons.gov.uk/ons/publications/ re-reference-tables.html?edition=tcm\%3A77-274529. Accessed December 2013. 
32. Christ SL, Lee DJ, Lam BL, et al. Assessment of the effect of visual impairment on mortality through multiple health pathways: structural equation modeling. Invest Ophthalmol Vis Sci. 2008;49(8):3318-23.

33. Czoski-Murray C, Carlton J, Brazier J, et al. Valuing conditionspecific health states using simulation contact lenses. Value Health. 2009;12(5):793-9.

34. National Institute for Health and Care Exellence. Final appraisal determination: Ranibizumab for treating visual impairment caused by macular oedema secondary to retinal vein occlusion. 2013. http://www.nice.org.uk/guidance/ta283/resources/macularoedema-retinal-vein-occlusion-ranibizumab-final-appraisaldetermination-document2. Accessed 15 May 2013.

35. Rubin GS, Munoz B, Bandeen-Roche K, et al. Monocular versus binocular visual acuity as measures of vision impairment and predictors of visual disability. Invest Ophthalmol Vis Sci. 2000;41(11):3327-34.

36. PSSRU. Personal Social Services Research Unit. Unit costs of health and social care. 2011. http://www.pssru.ac.uk/projectpages/unit-costs/2011/index.php. Accessed January 2013.

37. Colquitt JL, Jones J, Tan SC, et al. Ranibizumab and pegaptanib for the treatment of age-related macular degeneration: a systematic review and economic evaluation. Health Technol Assess. 2008;12(16):3-4 (9-201).

38. Claxton K, Martin S, Soares M, et al. Methods for the estimation of the NICE cost effectiveness threshold. University of York, Centre for Health Economics. 2013: Research paper 81.

39. National Institute for Health and Care Exellence. Ranibizumab for treating choroidal neovascularisation associated with pathological myopia. NICE technology appraisal [TA298]. 2013. http://www.nice.org.uk/guidance/ta298/resources/guidanceranibizumab-for-treating-choroidal-neovascularisation-associatedwith-pathological-myopia-pdf. Accessed 15 May 2013.

40. Novartis Pharmaceuticals UK Ltd. Lucentis (ranibizumab) $10 \mathrm{mg} / \mathrm{ml}$ solution for injection. EU summary of product characteristics. 2013. http://www.medicines.org.uk/EMC/medicine/
19409/SPC/Lucentis $+10+\mathrm{mg}+\mathrm{ml}+$ solution + for+injection/. Accessed July 2013.

41. Leveziel N, Tufail A, Yu HG et al. Ranibizumab treatment outcome in visual impairment due to myopic choroidal neovascularization: RADIANCE subgroup analysis based on baseline ocular characteristics [presentation 4956-D0066]. The Association for Research in Vision and Ophthalmology (ARVO) Annual Meeting; 4-8 May 2014; Orlando (FL).

42. Franqueira N, Cachulo ML, Pires I, et al. Long-term follow-up of myopic choroidal neovascularization treated with ranibizumab. Ophthalmologica. 2012;227(1):39-44.

43. Freitas-da-Costa P, Pinheiro-Costa J, Carvalho B, et al. AntiVEGF Therapy in myopic choroidal neovascularization: longterm results. Ophthalmologica. 2014 (epub ahead of print).

44. Ruiz-Moreno JM, Arias L, Montero JA, et al. Intravitreal antiVEGF therapy for choroidal neovascularisation secondary to pathological myopia: 4-year outcome. $\mathrm{Br} \mathrm{J}$ Ophthalmol. 2013;97(11):1447-50.

45. Sharma S, Bakal J. The value component of evidence-based medicine: the cost-utility of photodynamic therapy for pathologic myopia. Evid Based Ophthalmol. 2002;3(1):49-53.

46. Mitchell P, Annemans L, Gallagher M, et al. Cost-effectiveness of ranibizumab in treatment of diabetic macular oedema (DME) causing visual impairment: evidence from the RESTORE trial. Br J Ophthalmol. 2012;96(5):688-93.

47. Neubauer AS, Holz FG, Sauer S, et al. Cost-effectiveness of ranibizumab for the treatment of neovascular age-related macular degeneration in Germany: model analysis from the perspective of Germany's statutory health insurance system. Clin Ther. 2010;32(7):1343-56.

48. Novartis Pharmaceuticals UK Ltd. VISUDYNE (Verteporin) $15 \mathrm{mg}$, powder for solution for infusion. EU summary of product characteristics. 2012. http://www.medicines.org.uk/EMC/medicine/4656/ SPC/VISUDYNE $+15+\mathrm{mg} \% 2 \mathrm{c}+$ powder + for + solution + for + infusion/. Accessed July 2013. 